\title{
Cervicofacial Actinomycosis
}

\author{
Kiyoshi Shikino, MD, Masatomi Ikusaka, MD, PhD, and Toshihiko Takada, MD, PhD
}

Department of General Medicine, Chiba University Hospital, Chiba-city, Chiba pref. Japan.

KEY WORDS: Actinomyces; facial abscess; formation of fistulae.

J Gen Intern Med 30(2):263

DOI: $10.1007 / \mathrm{s} 11606-014-3001-z$

(C) Society of General Internal Medicine 2014

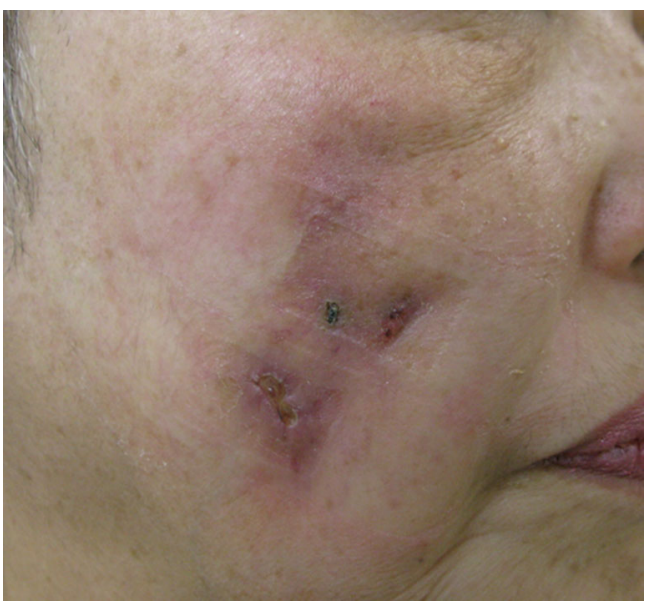

Figure 1. Indurated mass in the right cheek.

\begin{abstract}
A 62-year-old woman with a history of rheumatoid arthritis and on immunosuppressive agents presented with a two month history history of slowly progressive right facial swelling with recurrent eruptions. The symptom temporarily responded to short courses of antibiotics, but progressively worsened over time. Physical examination revealed dental caries in the right maxillary molar and a non-tender indurated mass in the right cheek (Fig. 1). Computed tomography revealed a facial abscess, fistulae and draining sinus tracts. Excision biopsy of the right cheek revealed a central neutrophilic, lobulated abscess with round basophilic masses, a narrow eosinophilic border, and thin basophilic radiating filaments at the periphery with a dense, granular core (Fig. 2), consistent with actinomycosis. After administration of amoxicillin $1500 \mathrm{mg} /$ day for six months, the symptoms resolved.
\end{abstract}

Cervicofacial actinomycosis is caused by Actinomyces, a normal inhabitant of the oral cavity. Precipitants for infection

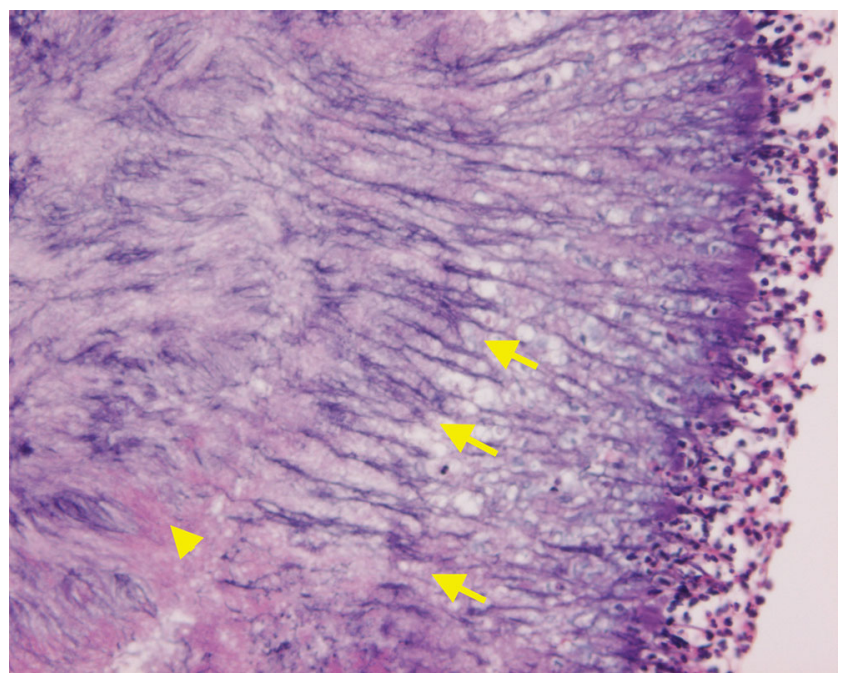

Figure 2. HE stain (high-power field): A central neutrophilic, lobulated abscess with round basophilic masses (arrowhead), and thin basophilic radiating filaments at the periphery (arrows)

include dental caries and mucosal injuries, leading to fistula and abscess formation. Poor oral hygiene and immunosuppression may be contributing factors. Self-destruction of abscesses and formation of fistulae are observed in chronic stages. Patients with actinomycosis tend to be misdiagnosed with malignancy or granulomatous disease. ${ }^{1}$ Appropriate diagnosis greatly influences prognosis. Treatment includes prolonged courses of antibiotics and often surgery.

Corresponding Author: Kiyoshi Shikino, MD; Department of General Medicine Chiba University Hospital, 1-8-1, Inohana, Chuo-ku, Chibacity, Chiba pref. Japan (e-mail: kshikino@gmail.com).

\section{REFERENCES}

1. Miller M, Haddad AJ. Cervicofacial actinomycosis. Oral Surg Oral Med Oral Pathol Oral Radiol Endod. 1998;85:496-508. 